\title{
Microgeographic body size variation in a high elevation Andean anole (Anolis mariarum; Squamata, Polychrotidae)
}

\author{
Brian C. Bock ${ }^{1}$, Angela M. Ortega ${ }^{1,2}$, Ana María Zapata ${ }^{3}$ \& Vivian P. Páez ${ }^{1}$
}

1. Instituto de Biología, Universidad de Antioquia, AA 1226, Medellín, Colombia; BrianBock1@gmail.com, vppaez@gmail.com

2. Laboratorio de Ecología Evolutiva de Reptiles, Instituto de Biología, Universidad Nacional Autónoma de México, C.P. 04510, Distrito Federal, México; amortega25@yahoo.com.mx

3. Departamento de Ciencias Forestales, Universidad Nacional de Colombia, Sede Medellín, AA 568, Medellín, Colombia. Current address: Subdirección de Control y Segimiento Ambiental, Corporación Autónoma Regional de Quindío, Calle 19N, No. 19-55, Armenia, Quindío, Colombia.

Received 20-XI-2008. C Corrected 08-III-2009. Accepted 07-IV-2009.

\begin{abstract}
Intra-specific body size variation is common and often is assumed to be adaptive. Studies of body size variation among sites should include or consider environmental and ecological variables in their designs. Additionally, reciprocal transplant or common garden studies will support which variables are really contributing to the observed body size variation. This study analyzed the microgeographic body size variation in Anolis mariarum, a small lizard endemic to Antioquia, Colombia. Parameters such as body size, shape, and lepidosis variation were quantified in 217 adult $A$. mariarum, belonging to six populations separated by less than $80 \mathrm{~km}$. Results showed that significant body size variation was not related to differences among sites in mean annual temperature, but covaried with mean annual precipitation, with the largest individuals occurring in dryer sites. Mark-recapture data obtained from 115 individuals from both the wettest and dryest sites from October 2004 to April 2005 showed that growth rates were higher at the latter. Eight males from each site were captured at the end of the mark-recapture study and reared for two months under identical conditions in a common garden study. Individuals from both sites grew faster when reared in the laboratory with food provided ad libitum. Although growth rates of males from the two populations did not differ significantly in the laboratory, males from the dryest site still maintained a significantly larger asymptotic body size in their growth trajectories. Multivariate analyses also demonstrated that both males and females from the six populations differed in terms of body shape and lepidosis. However, only female body size was found to covary significantly with an environmental gradient (precipitation). A. mariarum does not conform to Bergmann's rule, but the relationship found between mean body size and asympotic growth with mean annual precipitation at these sites needs further analysis. Generally, studies of intra-specific body size variation should consider a number of additional phenotypic traits to provide stronger baseline information on the degree of overall divergence among populations, including those likely to be selectively neutral, before interpreting results of analyses on the body size differences. Rev. Biol. Trop. 57 (4): 1253-1262. Epub 2009 December 01.
\end{abstract}

Key words: body size, growth rates, Bergmann's rule, morphometrics, lepidosis, geographic variation, common garden study, precipitation, temperature.

Intraspecific body size variation is common and is often assumed to have an adaptive basis. Recent meta-analyses of studies on endotherms (Ashton et al. 2000, Meiri \& Dayan 2003) have supported this premise by confirming that body sizes covary with environmental temperature (as measured by the surrogate variables of latitude or elevation) in the majority of the species examined, with larger individuals occurring in cooler climates in accordance with Bergmann's rule. However, results of comparable meta-analyses of studies 
on vertebrate ectotherms have been equivocal (Ashton 2002, Belk \& Houston 2002, Ashton \& Feldman 2003, Adams \& Church 2008, Pincheira-D et al. 2008), suggesting that body size variation in these species may not be adaptive (Van Voorhies 1996), or at least may not always be the result of a single generalized selection pressure (Angilletta \& Dunham 2003). Thus, the study of body size variation in ectotherms would seem to be best conducted intraspecifically or among closely related species, employing designs that include consideration of additional environmental factors.

Studies of intraspecific body size variation in ectotherms also should address additional considerations. In wide ranging species, the risk of pooling data on undetected cryptic species exists. Also, when comparing populations from different latitudes, one should control for elevational differences among sites, and vice versa. Finally, care should be taken to avoid comparing populations that markedly differ in their sympatries with predators, prey, or interspecific competitors (Ashton \& Feldman 2003, Roughgarden \& Fuentes 1977).

Even when an adequately designed study for an ectotherm species shows that body size covaries with a particular environmental variable, follow-up reciprocal transplant or common garden studies are required to determine whether these differences represent phenotypic responses to the different environments or reflect genetically based local adaptations (Berven 1982, Ferguson \& Talent 1993, Mousseau 1997, Lorenzon et al. 2001, Thorpe et al. 2005). Unfortunately, transplant studies suggesting an adaptive basis for body size variation often have low power due to limited sample sizes and insufficient replication. In the context of admonitions to employ null models in ecological research (Harvey et al. 1983, Gotelli \& Graves 1996, Gotelli 2001), before one over-interprets evidence for genetically based body size differences among populations, one needs an estimate of how much other presumably selectively neutral traits also differ among the demes. When significant and apparently genetically based body size differences exist among populations while differences in other neutral traits are lacking, one may more safely conclude the differences arose via selection and are not merely the result of genetic drift among isolated demes. Molecular markers might provide baseline information on the degree of variation in neutral characters, although the correspondence between levels of genetic and morphological variation is not always high (Merilä \& Crnokrak 2001, McKay \& Latta 2002). Information on levels of variation in other quantitative traits also could help provide a baseline against which levels of differentiation in the trait of interest (here, body size) could be interpreted.

In this study, microgeographic body size variation was quantified in Anolis mariarum (Barbour 1932), a small lizard endemic to the Antioquia Department, Colombia. The species does not occur in sympatry with other anoles in the studied areas. Also, the complex mountanous terrain throughout its restricted distribution produces considerable microgeographic variation in mean annual precipitation, even among sites at the same elevation, facilitating the independent assessment of the importance of these two environmental variables in influencing morphological differences among populations.

Furthermore, this study also considered lizard growth rates in the field and compared them with the two study areas where lizard body sizes were found to be most divergent, and conducted a common garden experiment to assess the relative contributions of environmental versus genetic factors affecting growth rates and asymptotic body sizes for these populations. Finally, intra-specific divergence in other quantitative traits was assessed to provide a null model to use when interpreting the body size differences documented.

\section{MATERIALS AND METHODS}

Comparisons of populations: Microgeographic morphometric variation was quantified in six A. mariarum populations located along a $80 \mathrm{~km}$ north-south transect of Cordillera 
Central, northern Andes, Colombia. Elevations of the sites varied from 1900 to $2700 \mathrm{~m}$, and although mean annual temperature of the sites was negatively correlated with elevation (Spearman $\mathrm{rho}=-0.94, \mathrm{p}<0.005$ ), mean annual precipitation was not (Spearman $\mathrm{rho}=-0.15$, $\mathrm{p}>0.10$ ).

All study sites suffered from some degree of human impact, ranging from relatively pristine sites, such as Caldas $\left(6^{\circ} 01^{\prime} 54^{\prime \prime} \mathrm{N}\right.$, $75^{\circ} 36^{\circ} 02^{\prime} \mathrm{W}$ ), where lizards occupied low riparian vegetation in natural and artificial clearings along the headwaters of the Medellín river, and San Vicente (6 $6^{\circ} 17^{\prime} 14^{\prime \prime}$ N, $75^{\circ} 20^{\prime} 10^{\prime}$ ' W), where individuals occupied isolated patches of herbaceous and shrubby vegetation, to more impacted sites where the habitat was comprised entirely of ornamental plants and fence posts along rural roadsides, such as the Belmira (6 $37^{\circ} 40^{\prime \prime} \mathrm{N}, 75^{\circ} 41^{\prime} 16^{\prime \prime}$ W), San Antonio de Prado (6 $6^{\circ} 11^{\prime} 21^{\prime \prime} \mathrm{N}$, $\left.75^{\circ} 40^{\prime} 44^{\prime \prime} \mathrm{W}\right)$, and Santa Elena (6 $6^{\circ} 17^{\prime} 22^{\prime}$ ' $\left.\mathrm{N}, 75^{\circ} 30^{\prime} 57^{\prime \prime} \mathrm{W}\right)$ sites, and especially the Santa Rosa de Osos $\left(6^{\circ} 44^{\prime} 27^{\prime \prime}\right.$ N, $75^{\circ} 28^{\prime} 42$ W) site, where lizards were caught perching on concrete road markers and refuse objects scattered along a major highway.

Body size variation was quantified by measuring snout vent length (SVL) of 217 adult (SVL $>45 \mathrm{~mm}$ ) A. mariarum individuals that had been collected from these six populations. To minimize preservation-induced variation among individuals (Lee 1982, Reed 2001), all lizards were measured at least one month after they had been fixed in $10 \%$ buffered formalin and stored in $70 \%$ alcohol.

In order to analyze shape and lepidosis differences among the sites, 11 additional morphometric and eight meristic (scale count) traits were selected from those commonly used in studies of intra and inter-specific morphological variation in anoles (Fulger 1977, Lee 1980, Lee 1987, Losos 1990, Losos et al. 1994; Malhotra \& Thorpe 1997). The morphometric characters measured to the nearest $0.01 \mathrm{~mm}$ were: trunk length measured on the right side between the insertion of the extremities; head length measured bilaterally from the anterior margin of the rostral scale to the anterior margin of the ear opening; mouth length measured from the anterior margin of the rostral scale to the union of the supralabial and infralabial scales; head width measured as the maximum distance across the region anterior to the ear openings; head height measured at the level of the eyes; snout length measured from the anterior margin of the rostral scale to the anterior margin of the eye; interorbital distance; dewlap base length in males; tail base width; forearm length measured bilaterally; and tibia length measured on the left hind limb.

Meristic characters were: number of scales between the supraorbital semicircles, minimum number of scales between the interparietal and the supraorbital semicircle measured bilaterally; minimum number of scales between the second canthal rows; number of post-rostal scales; number of supralabial scales to the center of the eye, measured bilaterally; number of infralabial scales to the center of the eye, measured bilaterally; number of loreal rows measured bilaterally; and number of subdigital lamelae on the second and third phalanges of the fourth toe of the left rear limb.

All data were recorded by the same person (AMO) over a two month period. Data recorded during the first week of this period were discarded and these individuals were remeasured to eliminate effects of initial practice-related changes in measurement criteria. All original morphometric variables were natural log transformed to improve normality and homogeniety of variances. Measurements recorded bilaterally were averaged and from the new resultant variables, those with the greatest precision and exactitude were selected (Sokal \& Rohlf 1995). The eight morphometric characters selected by these criteria were SVL, head length, width and height, mouth length, interorbital distance, tibia length, and forearm length. All eight scale counts exhibited comparable precision and exactitude, so none were eliminated from the analyses.

Many anole species, including A. mariarum (see results), are sexually dimorphic, so body size differences among the sites were inspected 
using separate ANOVA for each sex. For shape analyses, the effect of body size was removed by regressing each morphometric variable on SVL to obtain residuals for analyses (Bookstein et al. 1985). This procedure was not conducted for the meristic variables, given their lack of correlation with body size. Our A. mariarum individuals also proved to be sexually dimorphic for shape (see results), so shape analyses also were conducted separately for each sex. Multivariate analyses of shape variation require a minimum number of individuals per group that depends upon the total number of variables inspected (Klingenberg 1996). Thus, the San Antonio de Prado and San Vicente populations had to be excluded from the shape analyses due to insuficient sample sizes after separating male and female data. All populations were included in the analyses of the meristic data.

Descriminant function analyses (DFAs) were conducted to inspect for differences between populations in shape (size-adjusted morphometric characters) and lepidosis (meristic characters). Once the canonical variables (CVs) were obtained, the centroids for each group (median of all variables in the multivariate space) were compared using ANOVA.

Voucher specimens inspected from the Museo de Herpetología of the Universidad de Antioquia (MHUA) and Museo del Colegio San José de la Salle (CSJ) in Medellín, Colombia were: Belmira - MHUA 010149-010154, 010192-010200, 010211, 010241, 010253-010256, 010305010308, 010333-010339, 010345-010353, and CSJ 0569, 0866, 0956-0958; Caldas MHUA 010013, 010016, 010017, 010171010173, 010177, 010185, 010237, 010238, 010240, 010245-010249, 010323-010326, 010354-010389, 010432-010444; San Antonio de Prado: MHUA 010201-010206, 010445010455; Santa Elena - MHUA 010167-010170, 010413-010430, 010522-010536; San Vicente - CSJ 001-006, 0488-0493, 0496, 0497, 0501, 0503, 0504, 0531, 0536, 0840; Santa Rosa de Osos - MHUA 010314, 010315, 010317010319, 010340-010344, 010395-010400, 010507-010521.
Growth rate study: After documenting significant body size differences among the sites (see results), a growth rate study was initiated with individually marked lizards at the wettest and dryest sites. From October $12^{\text {th }}$, 2004 until April 1 $1^{\text {st }}, 2005$; one of us (AMZ) visited Caldas (mean annual precipitation $=2$ $500 \mathrm{~mm}$ ) and Santa Elena (mean annual precipitation $=1600 \mathrm{~mm}$ ) on seven and eight occasions, respectively, to capture and mark juvenile and adult lizards. Captured individuals were measured for SVL with a dial caliper to the nearest $0.1 \mathrm{~mm}$ and marked with individually unique combinations of toe clips. During the 168 days of the study, 115 individuals were marked at each site, of which 78 were recaptured at least once on subsequent visits. Analyses were limited to data on adult individuals $(\mathrm{n}=22$ Caldas and 36 Santa Elena males; $n=12$ Caldas and 6 Santa Elena females) because only one of the 21 juveniles that were marked was recaptured. We used the SVL of each individual on the day of its first and last capture (mean interval $=81$ days) to calculate its growth rate $(\mathrm{mm} /$ day). We also estimated population growth parameters for each sex at each site using the interval equation of the logistic growth model (Schoener \& Schoener 1978):

$$
L_{2}=\frac{L_{1} A}{\left[L_{1}+\left(A-L_{1}\right) e^{-r D}\right]}
$$

where $\mathrm{L}_{1}$ and $\mathrm{L}_{2}$ represent the SVLs of an individual on its first and last capture, respectively, and $\mathrm{D}$ is the number of days between these events. Estimates of the intrinsic population growth rate (r) and asymptotic body size (A), with their respective $95 \%$ likelihood confidence intervals, were obtained using non-linear regresion.

At the conclusion of the field growth rate study, eight adult males from each population were captured for use in a captive rearing study. All but one of these individuals had been captured previously, thus permitting comparison of their growth rates in the field and after transfer to the common garden study. However, thanks 
to the differences among these sites in mean SVL, the males collected from the Caldas site were significantly smaller than the males from the Santa Elena site (Caldas mean SVL= 49.0mm; Santa Elena mean $\mathrm{SVL}=52.1 \mathrm{~mm}$; t-test, $\mathrm{p}<0.005)$.

These 16 individuals were reared in pairs in cubical cages measuring $40 \mathrm{~cm}$ on each side in a laboratory in Medellín, where they experienced identical conditions of ambient temperatures and photoperiod cycles (elevation $=1$ $550 \mathrm{~m}$, mean temperature $=22 \cdot 5^{\circ} \mathrm{C}$ ). Cages were mist sprayed several times daily and food (live caught arthropods) and water was provided $a d$ libitum. After two months, individuals were measured again for SVL and their laboratory growth rates $(\mathrm{mm} /$ day) were calculated. We also estimated the two population growth parameters ( $\mathrm{r}$ and $\mathrm{A}$ ) for each laboratory group, using the same non-linear regresion method as with the field data.

Growth rates in the field were negatively correlated with lizard body size (Caldas, $\mathrm{r}=-0.74, \mathrm{p}<0.001$; Santa Elena, $\mathrm{r}=-0.70$, $\mathrm{P}<0.001$ ), so ANCOVA were used to compare growth rates between populations, using SVL as a covariate. Growth rates in the common garden study were not correlated to body size (both groups pooled, $\mathrm{r}=0.05, \mathrm{p}>0.10$ ) because lizards of comparable body sizes were included in the study, so growth rates of the two groups in the laboratory could be compared with simple ANOVA. All statistical analyses were conducted using the JMP software package (SAS 1997).

\section{RESULTS}

Significant sexual dimorphism in body size was documented in A. mariarum (t-test, $\mathrm{p}<0.001)$. Body sizes also differed significantly among populations for males (ANOVA, $\left.\mathrm{F}_{5,128}=3.91, \mathrm{p}<0.005\right)$ and differed marginally for females (ANOVA, $\mathrm{F}_{5,79}=2.28, \mathrm{p}=0.054$ ), with Caldas individuals the smallest and Santa Elena individuals the largest. While body size variation was not related to mean annual temperatures at the sites (males, Spearman Rho $=-0.03, p>0.10$; females, Spearman Rho $=$ $0.03, p>0.10)$, body sizes were smaller at sites with greater mean annual precipitation (males, Spearman $r h o=-0.74, p=0.09$; females, Spearman $r h o=-0.97, p<0.005$ ).

Results from the field growth rate study in the Caldas and Santa Elena populations were equivocal. Although the estimates of the intrinsic growth rates for the two populations did not differ significantly for either sex (Table 1), ANCOVA indicated that, after controlling for body size, Santa Elena males grew significantly faster than Caldas males (ANCOVA, $\mathrm{F}=13.8$, $\mathrm{p}<0.001$ ), while female growth rates in the two populations did not differ (ANCOVA, $\mathrm{F}=$ $0.1, p>0.10)$. The non-linear regresion analysis

TABLE 1

Logistic growth non-linear regresion estimates of population intrinsic growth rates ( $r$ ) and asymptotic body sizes (A) in the field for each sex at the Caldas and Santa Elena sites

\begin{tabular}{|c|c|c|c|c|c|}
\hline \multirow[b]{2}{*}{ Females } & \multicolumn{2}{|c|}{ Caldas } & \multicolumn{2}{|c|}{ Santa Elena } & \multirow[t]{2}{*}{ Sign. } \\
\hline & $\mathrm{r}$ & Lower CI & Upper CI & $\mathrm{r}$ & \\
\hline \multirow{7}{*}{ Males } & 0.022 & 0.006 & 0.024 & 0.013 & n.s \\
\hline & A & Upper CI & Lower CI & A & \\
\hline & 50.5 & 54.2 & 51.4 & 53.2 & n.s. \\
\hline & $\mathrm{r}$ & Lower CI & Upper CI & $\mathrm{r}$ & \\
\hline & 0.012 & 0.009 & 0.010 & 0.008 & n.s. \\
\hline & A & Upper CI & Lower CI & A & \\
\hline & 51.0 & 52.1 & 54.8 & 55.6 & $*$ \\
\hline
\end{tabular}

Significant differences determined by the lack of overlap of their respective $95 \%$ confidence intervals. 
also showed that Santa Elena males had a significantly larger asymptotic body size than the Caldas males (Table 1, Fig. 1).

Males from both populations significantly increased their size-ajusted growth rates when brought to the laboratory (Caldas, ANCOVA, $\mathrm{F}=5.4, \mathrm{p}<0.05$; Santa Elena, ANCOVA, $\mathrm{F}=$ $10.6, \mathrm{p}<0.005)$, where both groups thereafter grew at comparable rates (t-test, $\mathrm{p}>0.10$ ). Nonlinear regression analyses also showed that males from both populations significantly increased their intrinsic growth rates in the laboratory, while the respective estimated asympotic body sizes of the two groups did not change (Table 2).

To inspect for the existence of interpopulational differences in other quantitative traits, we further analyzed the original data set obtained from lizards collected at the six sites. Multivariate analyses of the size-corrected shape variables for males showed the four populations with adequate sample sizes differed significantly in their projections onto both CV1 and CV2 (ANOVA, $\mathrm{F}_{3,107}=28.6, \mathrm{p}<0.001$ and $\mathrm{F}_{3,176}=15.4, \mathrm{p}<0.001$, respectively). Females from these populations also showed significant shape differences, as evidenced by their scores on CV1 and CV2 (ANOVA; $\mathrm{F}_{3,67}=32.01$, $\mathrm{p}<0.001$ and $\mathrm{F}_{3,67}=15.76, \mathrm{p}<0.001$, respectively). Finally, there were significant differences in lepidosis among the six populations

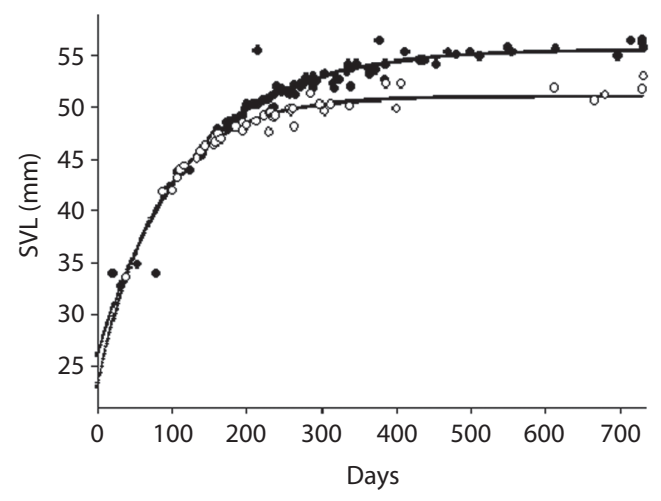

Fig. 1. Logistic growth curves obtained by non-linear fitting of male field growth data at each site to the logistic equation. Open circles $=$ Caldas, filled circles $=$ Santa Elena.

(data for both sexes combined) as shown by their projections onto CV1 (ANOVA, $\mathrm{F}_{5,137}=$ 28.28, $\mathrm{p}<0.001$ ) and CV2 (ANOVA, $\mathrm{F}_{5,137}=$ $14.65, \mathrm{p}<0.001)$.

Male and female shape and lepidosis differences did not covary with precipitation (Spearman tests, p's $>0.10$ ), but mean annual temperature at the sites was marginally correlated with scores of females on shape CV1 (Spearman $\mathrm{Rho}=-0.95, \mathrm{p}=0.051$ ) and scores of males on shape CV2 (Spearman Rho=-0.95, $\mathrm{p}=0.051$ ).

TABLE 2

Logistic growth non-linear regresion estimates of population intrinsic growth rates ( $r$ ) and asymptotic body sizes $(A)$ in the field and laboratory for males from the Caldas and Santa Elena sites

\begin{tabular}{|c|c|c|c|c|}
\hline \multirow[b]{2}{*}{ Caldas } & \multicolumn{2}{|c|}{ Field } & \multirow{2}{*}{$\begin{array}{c}\text { Laboratory } \\
\text { r }\end{array}$} & \multirow[t]{2}{*}{ Sign. } \\
\hline & $\mathrm{r}$ & Upper CI & & \\
\hline \multirow{7}{*}{ Santa Elena } & 0.012 & 0.016 & 0.019 & $*$ \\
\hline & A & Upper CI & A & \\
\hline & 51.0 & 52.1 & 51.9 & n.s. \\
\hline & $\mathrm{r}$ & Upper CI & $\mathrm{r}$ & \\
\hline & 0.008 & 0.010 & 0.028 & $*$ \\
\hline & $\mathrm{A}$ & Upper CI & A & \\
\hline & 55.6 & 56.6 & 55.7 & n.s. \\
\hline
\end{tabular}

Significant differences determined by the lack of overlap with the field $95 \%$ confidence intervals (sample sizes did not permit estimation of laboratory confidence intervals). 


\section{DISCUSSION}

A simple study only comparing body sizes among the six sites would have concluded that A. mariarum does not conform to Bergmann's rule, but that differences in mean annual precipitation somehow contribute to the body size differences documented. A follow-up study documenting faster growth rates at the dryer site also might have spectulated that lizards are larger there because dryer conditions may afford lizards better forraging or basking opportunities. Finally, a common garden study showing an increase in growth rates in males from both populations when reared under warmer temperatures with ad libitum food provided, but without altering their significantly different growth asymptotes, might have concluded that these two populations differ genetically for this trait. Because we included consideration of other traits besides body size in this study, we only adhere to the first of these conclusions.

Bergmann's rule was initially formulated for endotherms based upon an explicit physiological argument (Bergmann 1847). However, with ectotherms, some have argued that larger body sizes at higher latitudes or elevations may merely be an unadaptive epiphenomenon related to how cells divide under cooler conditions (van der Have \& de Jong 1996, Van Voorhies 1996, Atkinson \& Sibly 1997). Others have argued that with ectotherms, their adaptive responses to cooler environments likely represent complex interactions on how the thermal constraints of their environments influence their thermoregulatory activities (Grant \&Dunham 1988, Hertz et al. 1993, Bashey \& Dunham 1997, Angilletta \& Dunham 2003). This may explain why recent meta-analyses have failed to show clear patterns of body size variation with elevation or latitute in ectotherms (Ashton 2002, Belk \& Houston 2002, Ashton \& Feldman 2003, Adams \& Church 2008, Pincheira-D et al. 2008). However, A. mariarum is a species that occurs at remarkably high elevations for its genus, and so might be expected to be more likely to show some consistent pattern of body size variation with environmental temperature. Yet our analyses found no such evidence.

Even so, we have shown that $A$. mariarum exhibits considerable morphological variability on a micro-geographic scale, with significant differences among populations in all eight of the independent tests we conducted. Because we considered both mean annual temperature and precipitation in this study, 16 separate tests for an association between environmental and morphological variation were possible (temperature and precipitation effects on body size and shape CV1 and CV2 for both sexes, plus lepidosis CV1 and CV2 for the two sexes combined). Of these, three comparisons produced significant Spearman correlations, but a sequential Bonferroni adjustment (Holm 1979) to achieve an experiment-wide alpha level of 0.05 left only the precipitation/female body size relationship still significant. The marginally significant precipitation/male body size trend was in the same direction. This, considered along with the evidence of fixed differences in asymptotic male body sizes in the wettest and dryest populations, argues that while most of the morphological differences among populations may be selectively neutral, this particular association warrants further study.

However, in spite of the evidence that males grew faster at the dryest site, we feel it is premature to conclude that the larger body sizes documented there were necessarily due to these higher growth rates. Mean body size in a population of ectotherms also may be influenced by mortality rates, the intensity of sexual selection, or other factors related to life history evolution (Dunham et al. 1989, Grant \& Dunham 1990, Stamps 1999, Shine et al. 2002, Pearson et al. 2002a, Pearson et al. 2002b, Angilletta et al. 2004).

Finally, the fact that male A. mariarum from the wettest site stoped growing at a significantly smaller asymptotic body size, even when reared under identical laboratory conditions with males from the dryest site, does not necessarily constitute demonstration of a fixed genetic differences between these two populations. If asymptotic body size is phenotypically 
plastic in A. mariarum, perhaps determined by egg incubation conditions (Joanen et al. 1987, Rhen \& Lang 1995, Hare et al. 2004, Nelson et al. 2004, Goodman 2008) or growth trajectories established shortly after hatching (Campbell \& Echternacht 2003), then our common garden study of adult individuals would be incapable of detecting it.

In summary, by evaluating multiple environmental and phenotypic variables in this study, and using the results of these analyses as a baseline null model, stronger evidence has been provided that precipitation could be influencing growth rates and asymptotic body sizes in these $A$. mariarum populations. The fact that so many aspects of the phenotype of A. mariarum varied among these populations argues that studies of intra-specific morphological variation should not assume that only selectively important phenotypic traits will differ among reproductively isolated demes.

\section{ACKNOWLEDGMENTS}

This study was financed by a grant from the Fondo Colombiano de Investigaciones Científicas y Proyectos Especiales "Francisco José de Caldas" (Colciencias) to VPP and BCB and the Comité para el Desarrollo de la Investigación (CODI) of the Universidad de Antioquia. We thank the Museo del Colegio San José de La Salle and Museo de Herpetología, Universidad de Antioquia for access to specimens and the members of the Grupo Herpetológico de Antioquia for assistance with the field work. We also thank the Laboratorio de Ecología y Conservación Ambiental of the Departamento de Ciencias Forestales of the Universidad Nacional de Colombia, Sede Medellín, for housing the captive rearing study. Fernando Castro, Nicolas Jaramillo, and Anita Malhotra provided useful comments on an early version of the manuscript.

\section{RESUMEN}

Se reporta diferencias en el tamaño corporal entre individuos adultos de seis poblaciones de Anolis mariarum (Squamata: Polychrotidae), separadas por una distancia de hasta $80 \mathrm{~km}$. Esta variación no se relacionó con las diferencias en las temperaturas promedio anuales que existen entre los sitios analizados, pero sí covarió con la precipitación promedio anual, con los individuos de mayor talla habitando los sitios más secos. Datos de marca-recaptura del sitio más seco y más húmedo, mostraron que los individuos del sitio más seco tienen mayores tasas de crecimiento corporal. Bajo condiciones de laboratorio con alimento ad libitum, machos de ambos sitios crecieron más rápido que en condiciones naturales. Aunque las tasas de crecimiento de machos de las dos poblaciones no difirieron significativamente en el laboratorio, los machos del sitio más seco mantuvieron tamaños corporales asintóticos en sus trayectorias de crecimiento que fueron significativamente mayores. Análisis multivariados mostraron que tanto los machos como las hembras de las seis poblaciones difieren en la forma corporal y en lepiodosis, pero la única variable que covarió de manera significativa con un gradiente ambiental fue el tamaño corporal con la precipitación. Estudios de variación intraespecífica en el tamaño corporal deben considerar otras caracterísitcas fenotípicas adicionales para obtener una línea base sobre el grado de divergencia entre poblaciones, incluso aquellas que se consideran neutrales.

Palabras claves: tamaño corporal, tasas de crecimiento, regla de Bergmann, morfometría, variación geográfica, estudio de jardín común, precipitación, temperatura.

\section{REFERENCES}

Adams, D.C. \& J.O. Church. 2008. Amphibians do not follow Bergmann's rule. Evolution 62: 413-420.

Angilletta, M.J., Jr. \& A.E. Dunham. 2003. The temperaturesize rule in ectotherms: simple evolutionary explanations may not be general. Am. Nat. 162: 332-342.

Angilletta, M.J., Jr., T.D. Steury, \& M.W. Sears. 2004. Temperature, growth rate, and body size in ectotherms: Fitting pieces of a life-history puzzle. Integr. Comp. Biol. 44: 498-509.

Ashton, K.G. 2002. Do amphibians follow Bergmann's rule? Can. J. Zool. 80: 708-716. 
Ashton, K.G. \& C.R. Feldman. 2003. Bergmann's rule in nonavian reptiles: turtles follow it, lizards and snakes reverse it. Evolution 57: 1151-1163.

Ashton, K.G., M.C. Tracy, \& A. de Queiroz. 2000. Is Bergmann's rule valid for mammals? Am. Nat. 156: 390-415.

Atkinson, D. \& R.M. Sibly. 1997. Why are organisms usually bigger in colder environments? Making sense of a life history puzzle. Trends Ecol. Evol. 12: 235-239.

Bashey, F. \& A.E. Dunham. 1997. Elevational variation in the thermal constraints on and microhabitat preferences of the greater earless lizard Cophosaurus texanus. Copeia 1997: 725-737.

Belk, M.C. \& D.D. Houston. 2002. Bergmann's rule in ectotherms: a test using freshwater fishes. Am. Nat. 160: 803-808.

Bergmann, C. 1847. Über die Verhälnisse der Warmeökonomie der Thiere zu ihrer Grosse. Gott. Stud. 1: 595-708.

Berven, K.A. 1982. The genetic basis of altitudinal variation in the wood frog Rana sylvatica. I. An experimental analysis of life history traits. Evolution 36: 962-983.

Bookstein, F.L., B. Chernoff, R. Elder, J. Humphries, G. Smith, \& R. Strauss. 1985. Morphometrics in evolutionary biology: the geometry of size and shape change, with examples from fishes. Special Publication 15. Acad. Natural Sci. Philadelphia, Philadelphia, Pennsylvania, USA.

Campbell, T.S. \& A.C. Echternacht. 2003. Introduced species as moving targets: changes in body sizes of introduced lizards following experimental introductions and historical invasions. Biological Invasions 5: 193-212.

Dunham, A.E., B.W. Grant, \& K.L. Overall. 1989. The interface between biophysical ecology and the population ecology of terrestrial vertebrate ectotherms. Physiol. Zool. 62: 335-355.

Ferguson, G.W. \& L.G. Talent. 1993. Life history traits of the lizard Sceloporus undulatus from two populations raised in a common laboratory environment. Oecologia 93: 88-94.

Fugler, C.M. 1977. Geographic variation in Cuban and Mesoamerican populations of Anolis sagrei Dumeril and Bribon (Reptlia: Iguanidae). J. Tenn. Acad. Sci. 25: 131-139.

Goodman, R.M. 2008. Latent effects of egg incubation temperatura on growth in the lizard Anolis carolinensis. J. Exper. Zool., 309A: 525-533.
Gotelli, N.J. 2001. Research frontiers in null model analysis. Global Ecol. Biogeogr. 10: 337-343.

Gotelli, N.J. \& G.R. Graves. 1996. Null Models in Ecology. Smithsonian Institution, Washington, D.C., USA.

Grant, B.W. \& A.E. Dunham. 1988. Thermally imposed time constraints on the activity of the desert lizard Sceloporus merriami. Ecology 69: 167-176.

Grant, B.W. \& A.E. Dunham. 1990. Elevational covariation in environmental constraints and life histories of the desert lizard, Sceloporus merriami. Ecology 71: 1765-1776.

Hare, K.M., C.G. Longson, S. Pledger \& C.H. Daugherty. 2004. Size, growth and survival are reduced at cool incubation temperatures in the temperate lizard Oligosoma suteri (Lacertilia: Scincidae). Copeia 2004: 383-390.

Harvey, P.H., R.K. Colwell, J.W. Silverton, \& R.M. May. 1983. Null models in ecology. Annu. Rev. Ecol. Systemat. 14: 189-211.

Hertz, P.E., R.B. Huey \& R.D. Stevenson. 1993. Evaluating temperature regulation by field-active ectotherms: the fallacy of the inappropriate question. Am. Nat. 142: 796-818.

Holm, S. 1979. A simple sequentially rejective multiple test procedure. Scand. J. Stat. 6: 65-70.

Joanen, T., L. McNease \& M.W.J. Ferguson. 1987. The effects of egg incubation temperature on post-hatching growth of American alligators, p. 533-537. In G.W.J. Webb, S.C. Manolis, \& P.J. Whitehead (eds.). Wildlife management: crocodiles and alligators. Surrey Beatty, Chipping, Norton, Australia.

Klingenberg, C.P. 1996. Multivariate allometry, p. 26-49. In L.F. Marcus, M. Corti, A. Loy, G.J.P. Naylor, \& D.E. Slice (eds.). Advances in Morphometrics. Plenum, New York, USA.

Lee, J.C. 1980. Variation and systematics of the Anolis sericeus complex (Sauria: Iguanidae). Copeia 1980: 310-320.

Lee, J.C. 1982. Accuracy and precision in anuran morphometrics: artifacts of preservation. Syst. Zool. 31: 266-281.

Lee, J.C. 1987. Anolis sagrei in Florida: phenetics of a colonizing species, II. Morphometric characters. Copeia 1987: 458-469.

Lorenzon, P., J.Colbert \& M. Massot. 2001. The contribution of phenotypic plasticity to adaptation in Lacerta vivipara. Evolution 55: 392-404. 
Losos, J.B. 1990. Ecomorphology, performance capability, and scaling of West Indian Anolis lizards: an evolutionary analysis. Ecol. Monogr. 60: 369-388.

Losos, J.B., D.J. Irschick \& T.W. Schoener. 1994. Adaptation and constraint in the evolution of specialization of Bahamian Anolis lizards. Evolution 48: 1786-1798.

Malhotra, A. \& R.S. Thorpe. 1997. Microgeographic variation in scalation of Anolis oculatus (Dominica, West Indies): a multivariate analysis. Herpetologica 58: 49-62.

McKay, J.K. \& R.G. Latta. 2002. Adaptive population divergence: markers, QTL and traits. Trends Ecol. Evol. 17: 285-291.

Meiri, S. \& T. Dayan. 2003. On the validity of Bergmann's rule. J. Biogeogr. 30: 331-351.

Merilä, J. \& P. Crnokrak. 2001. Comparison of genetic differentiation at marker loci and quantitative traits. J. Evol. Biol. 14: 892-903.

Mousseau, T.A. 1997. Ectotherms follow the converse to Bergmann's rule. Evolution 51: 630-632.

Nelson, N.J., M.B. Thompson, S. Pledger, S.N Keall \& C.H. Daugherty. 2004. Egg mass determines hatchling size, and incubation temperature influences post-hatching growth, of tuatara Sphenodon punctatus. J. Zool. Lond. 263: 77-87.

Pearson, D., R. Shine \& R. How. 2002a. Sex-specific niche partitioning and sexual size dimorphism in Australian pythons (Morelia spilota imbricata). Biol. J. Linn. Soc. 77: 113-125.

Pearson, D., R. Shine, \& A. Willians. 2002b. Geographic variation in sexual size dimorphism within a single snake species (Morelia spilota, Pythonidae). Oecologia 131: 418-426.

Pincheira-D, D., D.J. Hodgson, \& T. Tregenza. 2008. The evolution of body size under environmental gradients in ectotherms: why should Bergmann's rule apply to lizards? BMC Evol. Biol. 8: 68.
Reed, R.N. 2001. Effects of museum preservation techniques on length and mass of snakes. Amphibia-Reptilia 22: 488-491.

Rhen, T. \& J.W. Lang. 1995. Phenotypic plasticity for growth in the common snapping turtle: effects of incubation temperature, clutch, and their interaction. Am. Nat. 146: 726-747.

Roughgarden, J.D. \& E. Fuentes. 1977. The environmental determinants of size in solitary populations of West Indian Anolis lizards. Oikos 29: 44-51.

SAS, 1997. JMP Version 3.2. SAS Institute Inc., Cary, North Carolina, USA.

Schoener, T.W. \& A. Schoener. 1978. Estimating and interpreting body-size growth in some Anolis lizards. Copeia 1978: 390-405.

Shine, R., R.N. Reed, S. Shetty, \& H.G. Cogger. 2002. Relationships between sexual dimorphism and niche partitioning within a clade of sea-snakes (Laticaudinae). Oecologia 133: 45-53.

Sokal, R.R. \& F.J. Rohlf. 1995. Biometry. The Principles and Practice of Statistics in Biological Research. W.H. Freeman, New York, New York, USA.

Stamps, J.A. 1999. Relationships between female density and sexual size dimorphism in samples of Anolis sagrei. Copeia 1999: 760-765.

Thorpe, R.S., J.T. Reardon \& A. Malhotra. 2005. Common garden and natural selection experiments support ecotypic differentiation in the Dominican anole (Anolis oculatus). Am. Nat. 165: 495-504.

van der Have, T.M. \& G. de Jong. 1996. Adult size in ectotherms: temperature effects on growth and differentiation. J. Theor. Biol. 183: 329-340.

Van Voorhies, W.A. 1996. Bergmann's size clines: a simple explanation for their occurrence in ectotherms. Evolution 50: 1259-1264. 